\title{
Leveraging BI Systems to Overcome Infobesity: A Comparative Analysis of Incumbent and New Entrant firms
}

\author{
Ojaswi Malik \\ The University of Hong Kong \\ ojaswim@connect.hku.hk \\ Abhishek Kathuria \\ Indian School of Business \\ abhishek_kathuria@isb.edu
}

\author{
Ankur Jaiswal \\ Indian School of Business \\ ankur_jaiswal@isb.edu \\ Prasanna Karhade \\ University of Hawaii Manoa \\ karhade@hawaii.edu
}

\begin{abstract}
Infobesity is a condition whereby firms collect more information than they need or more information than they can efficiently use. As both incumbent firms and new entrant firms face different information-rich technological and economic environments, they are at a greater risk of infobesity which can compromise their innovation outcomes. In this study we leverage a research design that integrates inductive analytics and abductive discovery to uncover how incumbent and new-entrant firms leverage Business Intelligence systems and digital collaboration activities to innovate in the face of infobesity. We find that new entrant firms encounter a threshold effect governed by the use of BI systems to filter information from their customer network. On the other hand, we found that while most incumbents are able to innovate, there are uninventive incumbents that are unable to develop new products when they deploy only moderate levels of BI systems to filter their supplier data.
\end{abstract}

\section{Introduction}

Infobesity is a condition characterized by information overload whereby firms collect more information than they need or more information than they can efficiently use. Infobesity can limit firms' workers' attention capacity thereby making it increasingly difficult to effectively use all available information. As firms' information environment continues to get dominated with technological investments and advances, the challenge of infobesity is not diminishing anytime soon. While the innovation activity of large incumbent and small new entrant firms is influenced by considerably different technological and economic environments [1] - both incumbents and new entrants are at a risk of infobesity which can compromise their innovation outcomes. Hence, it is essential to examine the differences in how both incumbents and new entrants equip themselves with capabilities that can transform the excess information and make it value-adding.

One such capability involves implementing Business Intelligence systems for improving innovation outcomes and firm performance [2-5]. By offering advanced analytical capabilities, Business Intelligence systems offer a technology-based solution to cope with infobesity. These systems can help organizations filter through excess information to develop new products, nurture customer relationships, and target the right customers [6]. While Business Intelligence systems are a technology-based mechanism to cope with infobesity, firms can also benefit from digitally enabled collaborations with its partners which enable new combinations of knowledge.

These mechanisms to innovate in the presence of infobesity - a technical mechanism that relies on Business Intelligence system use versus a sociotechnical mechanism that relies on digitally enabled collaboration with partners - do not exist in isolation and thus their emergent interplay warrants research attention. Hence, in this study we put forward the following question:

How do incumbent and new entrant firms implement BI systems to innovate in the face of infobesity?

Recent studies have begun to explain how firms innovate in the presence of information overload [711]. However, there remains a gap in comprehensively understanding the complex interplay of multiple factors residing across multiple levels of analyses that differ for explaining innovation at incumbent and new entrant firms. We aim to bridge this gap by leveraging 
a research design that has gained credence in recent Information Systems scholarship [9, 12-14]. This research methodology integrates induction-based data-driven analytics approaches with abduction to uncover emergent patterns from the data.

A research design predicated upon the deductive paradigm [7] does not support a data-first approach to discovery of emergent patterns explaining firms' performance outcomes. Deductive research designs rely on prior theory, making them confirmatory in nature and thus, are not able to learn emergent relationships from the data. In contrast, inductive research designs adopt a "data-first" stance which makes them better equipped for discovering emergent combinations of factors (across levels) from the data. Furthermore, processes that facilitate innovation reside at various levels of analyses - within the firm, in the socio-technological environment, across collaborators beyond the firm, and the environment. We maintain that a multilevel theoretical assessment is necessary for investigating innovation processes.

Hence, decision tree induction serves as the basis for identifying tacit patterns in the data. This serves as an input to the abductive discovery process which involves understanding these patterns to develop the best generalized explanations. Decision tree induction allows us to reveal key pathways of predictors at different levels of analyses that elucidate how deploying business intelligence systems to filter information can aid in overcoming infobesity and enable firm-wide innovation outcomes. Through abduction, we summarize our key theoretical findings to offer the best possible explanations and complete the knowledge creation cycle.

We analyze a unique survey dataset collected from Chief Executive Officers, Chief Financial Officers, Chief Information Officers, Chief Marketing Officers and other senior managers from a sample of more than two hundred U.S. firms about their information overload and innovation activity. Data was collected on the degree of implementing Business Intelligence systems, and Digitally Collaborating with firms' partners across the value chain. Furthermore, extensive data about information overload experienced by the firms, sourced from information systems including Supply Chain Management, Customer Relationship Management, and Enterprise Resource Planning systems was also collected.

We find that new entrant firms encounter a threshold effect governed by the use of BI systems to filter information from their customer network. Specifically, new-entrant firms that extensively deploy BI systems in order to make sense of customerside data are more likely to launch new products. On the other hand, we found that while most incumbents are able to innovate, there are uninventive incumbents that are unable to develop new products. This is when incumbents deploy only moderate levels of BI systems to filter their supplier data, do not digitally collaborate with their supplier network, and have an extremely small network of supplier they are unable to innovate.

The rest of this manuscript is organized as follows. In the next section, we present an overview of related literature. Subsequently, we describe the data used in the empirical investigation and the key information attributes (i.e., factors that associated with firm innovation outcomes) essential to our theory development. We then elaborate on the tree induction methodology. In the next section, we present findings from the sequence of decision tree induction and abduction. We conclude by discussing the implications of our findings and offering rich implications of our research.

\section{Related Literature}

\subsection{Innovation and Infobesity}

Open innovation has transformed innovation processes by allowing firms' partners, including its suppliers and customers, to contribute to innovation outcomes [15, 16]. Accordingly, the new product development activity requires the firms' knowledge workers to rely on repeated interactions with multiple socio-technical sources of information that allow for experimentation and thereby innovation [17-19]. As the firm's information environment becomes increasingly complex, it is getting exposed to infobesity [20, 21]. Characterized by information overload, infobesity is a condition whereby firms collect more information than they need or can efficiently use $[22,23]$.

The increasing complexity in the firm's information environment is influenced by various sources [24]. These sources of information exist at different levels for the firm including the firm-level, technology use level, partner-level, and industry level $[25,26]$. A firm's digital resource endowments influences the quantity and quality of the firm's information environment [27, 28]. Prior research has established that IT-enabled capabilities related to information management have a positive impact on the organizations' performance such as productivity enhancement, profitability improvement, cost reduction, etc. [29, 30]. Such IT-enabled capabilities play an important role in developing other firm capabilities for customer management, process management, and performance management which in turn influence customer, financial, human resources, and organizational effectiveness measures of firm 
performance [29]. By implementing Customer Relationship Management and Supply Chain Management systems, firms are able to expand their knowledge sources by acquiring vital information from their value chain, and can thereby improve their innovation outcomes [31-35]. However, the use of these technologies also exposes the firm to infobesity at the firm and technology use level [36].

Moreover, information existing at the partner level add to the firms' sources of infobesity. This is due to the unequal distribution of knowledge within the organization and its environment which incentivizes the firm to participate in collaborative activities to access additional knowledge [37]. Firms can establish multiple partnerships with suppliers and customers in its value chain network to access a larger variety of information [38]. By gaining new and diverse knowledge from its partners, the firm is more likely to face an excess load of information. Furthermore, with increased technical capital, industries' decision-making speed has increased, along with quicker production of high-quality products and services [39]. This has led to fast-paced and dynamic industries witnessing a fast pace of innovation or high clockspeed [40] which creates an additional level of infobesity at the industry-level.

\subsection{Coping with infobesity - BI Systems}

Infobesity in organizations can create technostress from information overload which leads to negative reactions such as frustration and dissatisfaction [20, 41]. This abundance of data can hinder productivity and performance of knowledge workers which can hinder creativity and innovation [36]. Hence, this requires the firm to be equipped with firm-wide capabilities that can transform the excess information and make it value-adding.

By offering advanced analytical capabilities, BI systems are a technology-based solution to cope with infobesity in organizations [6, 26, 29, 42]. Past research has shown that implementing BI systems can help organizations in developing new or improved products and services, enriching organizational intelligence, targeting the right customers and even nurturing customer relationships [2-6, 43].

\subsection{Large Incumbent versus Small Entrant Firms}

Achieving mass-market penetration and possessing large market shares enables incumbent firms to grow and establish themselves. This includes building influential power, a trustworthy reputation, invaluable relationships as well as fiscal resources.
These capabilities motivate incumbents to continue developing process innovations that tend to favor established designs [44, 45]. On the other hand, smaller new entrant firms and their innovation activity is influenced by considerably different technological and economic environments [1].

The exponential increase in digitalization can improve and threaten the innovation activity of both incumbents and new entrants [46, 47]. For instance, greater use of technologies pose a challenge to incumbents' established mindsets and identities [17, 48]. and make drastic and difficult changes within the firm and in the surrounding environment [49, 50]. With an abundance of new information, strategic leaders of both incumbents and new entrants need to mobilize and reconfigure their capability configurations in order to dynamically adjust to the evolving opportunity landscape [51].

As incumbent and new-entrant firms face vastly different challenges, it is essential to uncover how these two types of firms leverage BI systems to innovate in the presence of infobesity. Hence, this study aims to open the black box of innovation by unveiling how firms employ digitally enabled data analytical capabilities such as business intelligence (BI) systems to make better sense of the abundant information at hand. Our research methodology allows us to comprehensively understand the complex interplay of multiple levels of factors that can establish pathways for firms to cope with infobesity and improve their innovation outcome.

\section{Method}

\subsection{Data}

This study uses survey data collected from a sample of 246 U.S. firms. Data collection was facilitated by a reputed market research firm. The survey respondents include presidents, vice presidents (VPs), chief executive officers (CEOs), chief financial officers (CFOs), chief information officers (CIOs), and other senior managers of the firms in the sample. The distribution of firms' size, age and revenues in the sample is representative of the population of US firms from key industries.

Data was collected on the socio-technical efforts undertaken by the firms to facilitate innovation. This includes extensive data on collaboration activities conducted by the firm with its business partners across the value chain. We undertook extensive efforts during survey design and after data collection to ensure high reliability and validity to reduce the risk of common methods bias, including using differing scale anchors for different questions, randomizing question order 
across respondents, and employing the marker variable test. We also validated the primary survey data with appropriate archival data sources (e.g., firm patent data in our survey was compared to U.S. Patent and Trademark Office (USPTO) data). Furthermore, the instrument was pilot tested in a smaller sample prior to large scale administration and was peerreviewed by a panel of expert IS academics.

In order to understand the differentiated underlying driving forces of small and big firms, we split our data set into Incumbent firms and Newentrant firms. We identified incumbent firms as those with high average sales and market share in the past three years. On the other hand, firms with low average sales and market share in the past three years were categorized as new-entrant firms. Accordingly, out of the entire sample, one hundred and fifty-four firms were identified as incumbents and the remaining ninety two firms were identified as new-entrant firms.

Both incumbents and new entrants were plagued with varying degrees of infobesity which can compromise their worker's attention capacity and ability to innovate. About fifty percent of incumbent firms and more than thirty percent of new entrant firms revealed that they faced infobesity as a result of implementing information systems such as SCM, CRM, and ERP systems. Thus, as firms' information environment continues to get dominated with technological investments, they are at a greater risk of infobesity. It is thus imperative for firms to optimally utilize the abundance of data they are exposed to in order to improve their innovation outcomes.

\subsection{Measures}

3.2.1. Innovation. Our key dependent variable is Innovation. We measure innovation by using data on the number of products a given firm has developed and introduced to the market $[7,16]$. Firms with no new products are classified as Not Innovative, whereas those firms with one or greater new products are classified as Innovative. Next, we describe the attributes we provided to induce trees and build our theory for both incumbent and new-entrant firms.

3.2.2. Customer-side Digital Collaboration and Supplier-side Digital Collaboration. Both customer-side digital collaboration and supplier-side digital collaboration were captured on a five-point scale $(1=$ No Collaboration; $5=$ Very Extensive Collaboration). They measure the extent to which a firm digitally collaborated with its customers and suppliers respectively to obtain time-relevant information about new products/services in its line of business. We collected information about a given firm's digital collaboration with its customers/suppliers through items such as collaboration to identify the timing of market needs for new products/services, and collaboration to filter information about market among other items [7, 37, $38,52]$.

3.2.3. Business Intelligence (BI) system use. We captured the impact of Business Intelligence (BI) system use as a way to filter information from the firms' partner network. The extent of use of BI systems is measured for both customer-side and supplier-side on a seven-point scales. Customer-side BI system use captures using BI systems to filter information from customers and Supplier-side BI system use captures using BI systems to filter information from suppliers [2, 3, 7].

3.2.4. Firm-level attributes. We measure four firmlevel information attributes - IT Investment, $R \& D$ Investment, Mergers and Acquisitions ( $M \& A)$ Activity, and Market Scope. IT Investment was measured as average spending on IT hardware, software, and services as a percentage of total sales [33, 42]. Firms were classified into high, low, and medium categories if IT Investment was greater than $16 \%$, less than $6 \%$, or otherwise, respectively. Similarly, firm's $R \& D$ Investment was categorized as high/medium/low based on average spending on R\&D. Firms with more than five M\&As were classified as exhibiting high $M \& A$ activity, less than three $M \& A$ s classified as low, and the remaining as exhibiting medium $M \& A$ Activity. Firms were classified as having one of three values for Market Scope namely representing International, Regional or Domestic firms.

3.2.5. Technology-use attributes. We explore the use of three systems - intra-organizational ERP systems, inter-organizational SCM systems and market-facing CRM systems. For SCM and CRM systems, we collected data on the proportion of suppliers and customers connected to the focal organization using these systems, respectively. We classified a firm as high SCM Use or CRM Use if more than $80 \%$ of suppliers or customers are connected to the firm using SCM or CRM systems, respectively [7]. Firms with less than $20 \%$ of suppliers and customers using SCM and CRM systems were classified as having low SCM Use and CRM Use respectively. Remaining firms were categorized as firms with medium SCM Use and CRM Use respectively. We asked firms if they used ERP systems to manage information. Firms were classified into No ERP Use and ERP Use categories [14]. 
3.2.6. Partner-level attributes. We captured the strength of the supplier and customer networks by measuring number of customers and the number of suppliers [52], which were categorized into high, medium, and low values based on top, middle, and lower one-third categories of values.

3.2.7. Industry-level attributes. A firm was classified as belonging to an industry with high Clockspeed if average product lifecycle was less than a year, low Clockspeed if average product lifecycle is more than two years, and medium Clockspeed otherwise [40].

\subsection{Research Design}

Our methodology to build theory consists of induction followed by abduction. In order to discover complex underlying relationships in the data that otherwise are tacit and left unidentified, we induce decision trees. Decision tree induction is a supervised machine learning methodology where the induction algorithm identifies the most informative attributes in the data that influence the outcome [8-10]. After identifying patterns in the data, we make sense of them by conducting abductive reasoning to develop the best possible generalized explanations. This iterative process integrates induction and abduction to test various choices, improves predictive performance, and ultimately completes the knowledge production cycle to develop theory.

Prior to inducing trees, we use a sixty-sixpercentage split to partition our data. We make use of the open source Weka data mining tool for data partitioning, inducing trees, and pruning trees [12, 13]. Data partitioning involves repeatedly drawing two random, mutually exclusive training and testing subsamples of observations from the data. After partitioning the data, the decision tree induction methodology involves two main steps: inducing the trees, followed by pruning the trees. Firstly, the C4.5 algorithm with an eighty percent confidence factor is used for inducing the trees on the training partition. Secondly, the induced trees are pruned using the testing partition which increases the robustness of the knowledge discovered from the trees. There are two key inputs for decision tree induction: (1) firms described by all information attributes and (2) innovation outcome of all firms. After employing the C4.5 induction algorithm, the output is a decision tree that unveils tacit relationships of attributes leading to similar final outcomes. The $\mathrm{C} 4.5$ algorithm utilizes the concepts of information entropy and information gain ratio to reduce impurity in determining which attributes lead to terminal nodes or leaves $[12,13]$. Hence, the tree induction methodology iteratively groups together firm-level observations that not only demonstrate similar information attributes, but also lead to the common final outcome. This hereby leads to the output decision trees retaining only the most informative attributes. As we split our dataset into incumbent and new-entrant firms, we retained two decision trees for each type of firm.

Table 1. Table of measures

\begin{tabular}{|c|c|}
\hline Level & Information Attribute \\
\hline \multicolumn{2}{|c|}{ Attributes for explaining Innovation } \\
\hline \multirow{2}{*}{$\begin{array}{l}\text { Digital } \\
\text { Collaboration } \\
\text { with Partners }\end{array}$} & $\begin{array}{l}\text { Customer-side Digital } \\
\text { Collaboration }\end{array}$ \\
\hline & $\begin{array}{l}\text { Supplier-side Digital } \\
\text { Collaboration }\end{array}$ \\
\hline \multirow{2}{*}{$\begin{array}{l}\text { Business } \\
\text { Intelligence } \\
\text { System use }\end{array}$} & Customer-side BI system use \\
\hline & Supplier-side BI system use \\
\hline \multirow{4}{*}{ Firm level } & IT investment \\
\hline & R\&D investment \\
\hline & M\&A activity \\
\hline & Market Scope \\
\hline \multirow{3}{*}{$\begin{array}{l}\text { Technology- } \\
\text { use level }\end{array}$} & Intra-organizational: ERP systems \\
\hline & $\begin{array}{l}\text { Inter-organizational: SCM } \\
\text { systems }\end{array}$ \\
\hline & Market-facing: CRM systems \\
\hline \multirow[t]{2}{*}{ Partner level } & Number of customers \\
\hline & Number of suppliers \\
\hline Industry level & Clockspeed \\
\hline \multicolumn{2}{|c|}{ Outcome: Innovation } \\
\hline $\begin{array}{l}\text { Innovation } \\
\text { outcome }\end{array}$ & Innovation (Yes or No) \\
\hline
\end{tabular}

The second stage of our research methodology is abductive reasoning which involves the explanation of the rules discovered in the induction process. The abduction process requires the researchers' expertise and judgement to offer the most plausible explanations, and not confirmative logic, for the observations (derived from induction) [53]. The process of abductive reasoning is fundamentally different from deductive reasoning in that deduction stems from the guaranteed presence of given evidence. Hence, conclusions drawn from deductive reasoning are necessarily true as they were based on facts that were true [53]. On the other hand, abduction requires judgement to arrive at inferences that are the best possible explanation of the evidence available.

\section{Results from Induction}

In order to maintain robustness, we rely on the three heuristics of (1) high prediction accuracy, (2) high parsimony, (3) high reliability to select the best 
representative tree each for incumbent firms and new entrant firms which are presented in Figure 1 and Figure 2 respectively. The most informative attribute is the topmost attribute in the best representative tree. Out of the thirteen inputs to the algorithm, the best representative tree identified the use of Business Intelligence Systems as the most informative attribute for explaining innovation in both incumbents and new entrants. Specifically, the decision tree for incumbent firms identified deploying BI systems to filter information from suppliers more valuable. On the other hand, the decision tree for new entrant firms identified deploying BI systems to filter information from customers to be more important. These findings lend credence to our core premise that BI systems have a substantial positive effect for firms to utilize their data in order to innovate. It is essential to clarify that the trees induced are not reflective of the exact rules used by decision makers in firms, but instead are robust approximations of the tacit underlying decision rationale. The patterns in the data revealed from inducing trees allows us to extract two main rules.

\begin{tabular}{|l|}
\hline \multicolumn{1}{|c|}{ How New Entrant Firms Innovate } \\
\hline Customer-Side BI System Use = Low: No \\
Customer-Side BI System Use = Medium \\
| Supplier-Side Digital Collaboration = Low: No \\
| | IT Investment = Low: No \\
| | IT Investment = Medium: Yes \\
| | IT Investment = High: Yes \\
| Supplier-Side Digital Collaboration = High: Yes \\
Customer-Side BI System Use = High
\end{tabular}

Figure 1. New Entrant firms

\subsection{Rule 1 - The Threshold Effect of Business Intelligence for New Entrants}

\author{
Rule 1.1. IF (Customer-side BI System Use = \\ Low) $\rightarrow$ No Innovation \\ Rule 1.2. IF (Customer-side BI System Use = \\ High) $\rightarrow$ Innovation Outcomes
}

The decision tree for new entrants revealed a threshold effect governed by the use of BI systems to filter information from firms' customer network. Newentrant firms that extensively deploy BI systems in order to make sense of customer-side data are more likely to launch new products. On the other hand, a minimal use of BI systems does not lead to a positive innovation outcome for new entrants.

This threshold effect is furthered by two other information attributes for incumbent firms. The innovation outcome of firms that deploy only moderate levels of BI systems to filter their customer data depends on their level of digital collaboration with their suppliers, and their IT spending. Firms that barely collaborate with their supplier network on aspects such as filtering market information or developing new product features are unable to innovate. Moreover, firms with a small IT investment are also unable to innovate. On the other hand, digitally collaborating with suppliers and investing heavily in IT hardware, software and services enables firm to develop and launch new products and services to the market.

Rule 1.3. IF (Customer-side BI System Use = Medium) AND (Supplier-side Digital Collaboration $=$ Low $) \rightarrow$ No Innovation

Rule 1.4. IF (Customer-side BI System Use = Medium) AND (Supplier-side Digital Collaboration $=$ Medium $)$ AND $($ IT Investment $=$ Low) $\rightarrow$ No Innovation

Rule 1.5. IF (Customer-side BI System Use = Medium) AND (Supplier-side Digital Collaboration $=$ Medium $)$ AND $($ IT Investment $=$ Medium/High) $\rightarrow$ No Innovation

\begin{tabular}{|l|}
\hline \multicolumn{2}{|c|}{ How Incumbent Firms innovate } \\
\hline Supplier-Side BI System Use = Low: Yes \\
Supplier-Side BI System Use = Medium \\
| Supplier-Side Digital Collaboration = Low \\
| | Number of suppliers = Low: No \\
| | Number of suppliers = Medium: Yes \\
| | Number of suppliers = High: Yes \\
| Supplier-Side Digital Collaboration = Medium: Yes \\
| Supplier-Side Digital Collaboration = High: Yes \\
Supplier-Side BI System Use = High: Yes
\end{tabular}

Figure 2. Incumbent firms

\subsection{Rule 2 - Uninventive Incumbents}

We discovered that about ninety percent of incumbent firms were able to develop and launch a new product or service to the market. Through the decision tree we were able to uncover the combination 
of attributes that pose as inhibitors to innovation for the remaining incumbent firms. While extensive deployment of BI systems to filter information from suppliers enables incumbents to be innovate, a moderate level of employing BI systems exposes the incumbents to become uninventive.

\section{Rule 2.1. IF (Supplier-side BI System Use = High)} $\rightarrow$ Innovation Outcomes

When the incumbents deploy only moderate levels of BI systems to filter their supplier data, do not digitally collaborate with their supplier network, and have an extremely small network of supplier they are unable to innovate.

\section{Rule 2.2. IF (Supplier-side BI System Use = Medium) AND (Supplier-side Digital Collaboration $=$ Low) $A N D$ (Number of suppliers $=$ Low $) \rightarrow$ No Innovation}

The decision tree revealed that all other combinations of information attributes facilitated innovation in incumbent firms. Hence, having a large supplier network and extensively digitally collaborating with their suppliers to filter information enables incumbents to be innovative. Furthermore, the decision tree also revealed that deploying BI systems only at a minimal level in order to make sense of supplier data also enables incumbents to be innovative.

Rule 2.3. IF (Supplier-side BI System Use = Medium) AND (Supplier-side Digital Collaboration $=$ Medium $/$ High $) \rightarrow$ Innovation Outcomes

\section{Rule 2.4. IF (Supplier-side BI System Use = Low)} $\rightarrow$ Innovation Outcomes

\section{Discussion - Abducting Away}

By inducing decision trees, we identified contextspecific rules which explained the combination of different predictors $[12,54,55]$ leading to innovation in incumbent and new-entrant firms. After inducing these rules from the decision trees, we perform abductive reasoning to offer the best plausible explanation of the patterns revealed. Doing so will extend the knowledge cycle by allowing us to identify different explanations, and ultimately arrive on the most plausible explanation for the discovered (induced) findings [12-14, 54, 55].

While digital technologies allow firms to leverage their networks and tap into a vast amount of market- facing data, it also exposes them to infobesity. This creates an abundance of information which is more than what firms need or can efficiently use $[15,20,22$, 23 , 56]. Infobesity in organizations can hinder productivity and performance which can have detrimental consequences on their decision-making and innovation activities [21, 36, 57]. As a large proportion of firms in our sample face high degrees of infobesity, it is of vital importance to examine how they can and cannot innovate activity in its presence. Furthermore, by splitting our sample into incumbents and new entrants, we are able to identify how both small and big firms leverage socio-technical capabilities at multiple levels of analyses to filter through vast amounts of information.

Both rules extracted from the induced trees reveal the importance of implementing Business Intelligence systems to usefully leverage their information and ultimately develop new products and services. On the one hand, incumbent firms rely on BI systems to filter information from suppliers to manage infobesity when creating new products and services. On the other hand, new entrant firms rely on BI systems to filter information from the customer-side to manage their information overload. The shift to open innovation has remolded innovation processes by allowing suppliers and customers to contribute to the new product development activity $[1,16]$. Our findings extend this conversation to reveal that while larger firms are dependent on the upstream supplier network, smaller firms rely on customer networks for their innovation outcomes.

Furthermore, incumbent firms are almost always able to innovate except for when they have minimal collaboration with their suppliers and have a small supplier network. This further confirms the reliance of incumbent firms on their upstream interorganizational supplier network. With years of developing long trusted and galvanized supplier relationships, incumbent firms' entrenched supplier network is a key capability that enables them to be innovative. Furthermore, we found that despite a low extent of usage of BI systems to filter through supplier-side information, these incumbent firms are still able to innovate. This reveals their strong supplier relationships equip them with enough information in order to be creative.

New entrant firms rely on BI systems to filter information from their customer networks. This reveals that smaller firms depend heavily on downstream information to get a pulse of the market in order to develop new products and services. New entrant firms invest heavily in their stock of IT endowments including hardware, software and services to enhance their innovation outcomes. These 
digitally enabled capabilities create the optimal creative space for new entrants for gathering information from their partners and then filtering it to identify key features.

A holistic understanding of firms' innovation outcomes relies on several socio-technological activities. While BI systems present a machine-based solution to innovate in the face of infobesity, firms have and continue to benefit from other collaborationbased interactions with their partners which enable new combinations of knowledge. Through this study we aim to open the black box of innovation by recognizing BI systems as an essential driver of filtering an excess of information. Furthermore, we have examined the differentiating mechanisms driving innovation in incumbent and new entrant firms.

Our study has certain limitations. Our data was collected from one CXO for each firm and hence is applicable at the organization level. This could imply that our work suffers from a degree of generalizability in the context of distinct operations of independent teams. However, we believe this limitation paves the way for future research in understanding the application of BI systems and other socio-technical capabilities to overcome infobesity at different levels within the organization $[58,59]$. We believe there are opportunities to conduct deeper level analyses by studying the different teams within the organization. Thus, moving forward, many fine-grained measures of infobesity can be constructed which differ with the nature of the team they seek to gauge. For instance, there is a growing body of literature on family-owned businesses which can be applied to the context of infobesity [42, 60]. Future research can compare different degrees on infobesity experienced by familyowned and non-family-owned business, and whether possessing vast capabilities such as BI systems can protect family-owned businesses from infobesity [61].

\section{Conclusion}

In this study, we unveiled the varied ways by which incumbent and new entrant firms employ digitally enabled data analytical capabilities to make better sense of the abundant information at hand. As incumbent and new entrant firms face vastly different challenges, it is essential to uncover how these two types of firms leverage BI systems to innovate in the presence of infobesity. We bridge this gap by leveraging a research design that integrates inductive analytics and abductive discovery.

We find that new entrant firms encounter a threshold effect governed by the use of BI systems to filter information from their customer network. Specifically, new-entrant firms that extensively deploy BI systems in order to make sense of customerside data are more likely to launch new products. On the other hand, we found that while most incumbents are able to innovate, there are uninventive incumbents that are unable to develop new products. This is when incumbents deploy only moderate levels of BI systems to filter their supplier data, do not digitally collaborate with their supplier network, and have an extremely small network of supplier they are unable to innovate.

\section{References}

[1] Z. J. Acs and D. B. Audretsch, "Innovation in large and small firms: an empirical analysis," The American Economic Review, vol. 78, no. 4, pp. 678-690, 1988.

[2] T. Ramakrishnan, J. Khuntia, A. Kathuria, and T. J. Saldanha, "An Integrated Model of Business Intelligence \& Analytics Capabilities and Organizational Performance," Communications of the Association for Information Systems, vol. 46, no. 1, p. 31, 2020.

[3] T. Ramakrishnan, A. Kathuria, and J. Khuntia, "Business Analytics Capability and Supply Chain Management," Americas Conference on Information Systems, 2018.

[4] T. Ramakrishnan, A. Kathuria, and T. J. Saldanha, "Business Intelligence and Analytics (BI\&A) Capabilities in Healthcare," in Theory and Practice of Business Intelligence in Healthcare: IGI Global, 2020, pp. 1-17.

[5] T. Ramakrishnan, J. Khuntia, A. Kathuria, and T. J. Saldanha, "Business intelligence capabilities," in Analytics and Data Science: Springer, 2018, pp. 15-27.

[6] D. D. Phan and D. R. Vogel, "A model of customer relationship management and business intelligence systems for catalogue and online retailers," Information \& Management, vol. 47, no. 2, pp. 69-77, 2010.

[7] P. Karhade and J. Q. Dong, "Innovation outcomes of digitally enabled collaborative problemistic search capability," MIS Quarterly, vol. 45, no. 2, pp. 693-718, 2021.

[8] P. Karhade and M. Shaw, "Rejection and selection decisions in the IT portfolio composition process: An enterprise risk management based perspective," in Americas Conference on Information Systems, 2007, p. 221.

[9] P. Karhade, M. J. Shaw, and R. Subramanyam, "Patterns in information systems portfolio prioritization," MIS Quarterly, vol. 39, no. 2, pp. 413434, 2015.

[10] P. P. Karhade, M. J. Shaw, and R. Subramanyam, "Patterns in strategic IS planning decisions: An inductive approach," in Americas Conference on Information Systems, 2009, p. 397.

[11] P. Karhade, A. Kathuria, O. Malik, and B. Konsynski, "Digital Platforms and Infobesity: A Research Agenda," in The Role of e-Business during the Time of Grand Challenges. WeB 2020. Lecture Notes in Business Information Processing, A. Garimella, P. 
Karhade, A. Kathuria, X. Liu, J. Xu, and K. Zhao Eds. Cham: Springer 2021, pp. 67-74.

[12] A. Kathuria, P. P. Karhade, and B. R. Konsynski, "In the realm of hungry ghosts: Multi-level theory for supplier participation on digital platforms," Journal of Management Information Systems, vol. 37, no. 2, pp. 396-430, 2020.

[13] P. Karhade and A. Kathuria, "Missing Impact of Ratings on Platform Participation in India: A Call for Research in GREAT Domains," Communications of the Association for Information Systems, vol. 47, no. 1, p. 19, 2020.

[14] O. Malik, P. Karhade, and A. Kathuria, "How Technology Use Drives Infobesity: An In-Depth Look at ERP Systems," in Pacific Asia Conference on Information Systems, 2021.

[15] R. Garud, P. Tuertscher, and A. H. Van de Ven, "Perspectives on Innovation Processes," The Academy of Management Annals, vol. 7, no. 1, pp. 775-819, 2013.

[16] M. Andrade Rojas, T. Saldanha, J. Khuntia, A. Kathuria, and W. F. Boh, "Overcoming Innovation Deficiencies in Mexico: Use of Open Innovation through IT and Closed Innovation through IT by Small and Medium Enterprises," in Hawaii International Conference on System Sciences, 2021, p. 617.

[17] C. Anthony and M. Tripsas, "Organizational identity and innovation," The Oxford handbook of organizational identity, pp. 417-435, 2016.

[18] T. Saldanha, A. Kathuria, J. Khuntia, and B. Konsynski, "Ghosts in the Machine: How Marketing and Human Capital Investments Enhance Customer Growth when Innovative Services Leverage Self-Service Technologies," Information Systems Research, 2021.

[19] T. J. V. Saldanha, A. Sahaym, S. Mithas, M. G. Andrade-Rojas, A. Kathuria, and H.-H. Lee, "Turning Liabilities of Global Operations into Assets: ITEnabled Social Integration Capacity and Exploratory Innovation," Information Systems Research, vol. 31, no. 2, pp. 361-382, 2020.

[20] P. Hemp, "Death by information overload," Harvard business review, vol. 87, no. 9, pp. 83-89, 2009.

[21] T. W. Jackson and P. Farzaneh, "Theory-based model of factors affecting information overload," International Journal of Information Management, vol. 32, no. 6, pp. 523-532, 2012.

[22] K. M. Sutcliffe and K. E. Weick, "Information overload revisited," in The Oxford handbook of organizational decision making: Oxford University Press, 2009.

[23] M. Tarafdar, C. Maier, S. Laumer, and T. Weitzel, "Explaining the link between technostress and technology addiction for social networking sites: A study of distraction as a coping behavior," Information Systems Journal, vol. 30, no. 1, pp. 96-124, 2020.

[24] J. Q. Dong, J. He, and P. Karhade, "The Penrose effect in resource investment for innovation: Evidence from information technology and human capital," European Conference on Information Systems Proceedings, 2013.

[25] H. Pirkkalainen, M. Salo, M. Tarafdar, and M. Makkonen, "Deliberate or Instinctive? Proactive and
Reactive Coping for Technostress," Journal of Management Information Systems, vol. 36, no. 4, pp. 1179-1212, 2019.

[26] T. S. Ragu-Nathan, M. Tarafdar, B. S. Ragu-Nathan, and Q. Tu, "The Consequences of Technostress for End Users in Organizations: Conceptual Development and Empirical Validation," Information Systems Research, vol. 19, no. 4, pp. 417-433, 2008.

[27] M. Andrade Rojas and A. Kathuria, "Competitive brokerage, information technology and internal resources," in International Conference on Information Systems, 2014.

[28] M. Andrade Rojas, A. Kathuria, and B. Konsynski, "Competitive Brokerage: How Information Management Capability and Collaboration Networks Act as Substitutes," Journal of Management Information Systems, vol. Forthcoming, 2021.

[29] S. Mithas, N. Ramasubbu, and V. Sambamurthy, "How Information Management Capability Influences Firm Performance," MIS Quarterly, vol. 35, pp. 237-256, 03/01 2011.

[30] J. Q. Dong, P. P. Karhade, A. Rai, and S. X. Xu, "How Firms Make Information Technology Investment Decisions: Toward a Behavioral Agency Theory," Journal of Management Information Systems, vol. 38, no. 1, pp. 29-58, 2021.

[31] A. Rai, R. Patnayakuni, and N. Seth, "Firm performance impacts of digitally enabled supply chain integration capabilities," MIS quarterly, vol. 30, no. 2, pp. 225-246, 2006.

[32] J. Gómez, I. Salazar, and P. Vargas, "Does information technology improve open innovation performance? An Examination of Manufacturers in Spain," Information Systems Research, vol. 28, no. 3, pp. 661-675, 2017.

[33] L. Kleis, P. Chwelos, R. V. Ramirez, and I. Cockburn, "Information technology and intangible output: The impact of IT investment on innovation productivity," Information Systems Research, vol. 23, no. 1, pp. 4259, 2012.

[34] L. Chen, J. Hsieh, A. Rai, and S. Xu, "How Does Employee Infusion Use of CRM Systems Drive Customer Satisfaction? Mechanism Differences Between Face-to-Face and Virtual Channels," MIS Quarterly, vol. Forthcoming, 2021.

[35] S. Dewan and F. Ren, "Information Technology and Firm Boundaries: Impact on Firm Risk and Return Performance," Information Systems Research, vol. 22, no. 2, pp. 369-388, 2011.

[36] S. Chandra, A. Shirish, and S. C. Srivastava, "Does technostress inhibit employee innovation? Examining the linear and curvilinear influence of technostress creators," Communications of the Association for Information Systems, vol. 44, no. 1, p. 19, 2019.

[37] C. A. Un, A. Cuervo-Cazurra, and K. Asakawa, "R\&D collaborations and product innovation," Journal of Product Innovation Management, vol. 27, no. 5, pp. 673-689, 2010.

[38] D. Faems, B. Van Looy, and K. Debackere, "Interorganizational collaboration and innovation: Toward a portfolio approach," Journal of product 
innovation management, vol. 22, no. 3, pp. 238-250, 2005.

[39] V. Sima, I. G. Gheorghe, J. Subić, and D. Nancu, "Influences of the Industry 4.0 Revolution on the Human Capital Development and Consumer Behavior: A Systematic Review," Sustainability, vol. 12, no. 10, p. $4035,2020$.

[40] H. Mendelson and R. R. Pillai, "Industry clockspeed: Measurement and operational implications," Manufacturing \& service operations management, vol. 1, no. 1, pp. 1-20, 1999.

[41] T. Ragu-Nathan, M. Tarafdar, B. S. Ragu-Nathan, and Q. Tu, "The consequences of technostress for end users in organizations: Conceptual development and empirical validation," Information systems research, vol. 19, no. 4, pp. 417-433, 2008.

[42] X. Ning, J. Khuntia, A. Kathuria, and P. Karhade, "Ownership and Management Control Effects on IT Investments: A Study of Indian Family Firms," in Proceedings of the International Conference on Information Systems (ICIS), 2020.

[43] V.-H. Trieu, "Getting value from Business Intelligence systems: A review and research agenda," Decision Support Systems, vol. 93, pp. 111-124, 2017.

[44] M. Gort and S. Klepper, "Time paths in the diffusion of product innovations," The Economic Journal, vol. 92, no. 367, pp. 630-653, 1982.

[45] J. Diekhof, "Do entrants increase incumbents' innovation activity? Escaping the lock-in, stimulating technological change and the transition towards environmentally friendly vehicles," Journal of Innovation Economics Management, vol. 16, no. 1, pp. 101-137, 2015.

[46] J. Q. Dong, P. Karhade, A. Rai, and S. X. Xu, "Dynamic adjustment of information technology, corporate governance, and firm profitability," European Conference on Information Systems Proceedings, 2013.

[47] J. Q. Dong, P. Karhade, A. Rai, and S. X. Xu, "Information technology in innovation activity of the firm: Theory and synthesis," European Conference on Information Systems Proceedings, 2013.

[48] N. Kammerlander, A. König, and M. Richards, "Why do incumbents respond heterogeneously to disruptive innovations? The interplay of domain identity and role identity," Journal of Management Studies, vol. 55, no. 7, pp. 1122-1165, 2018.

[49] S. Ansari, R. Garud, and A. Kumaraswamy, "The disruptor's dilemma: TiVo and the US television ecosystem," Strategic Management Journal, vol. 37, no. 9, pp. 1829-1853, 2016.

[50] A. König, M. Schulte, and A. Enders, "Inertia in response to non-paradigmatic change: The case of meta-organizations," Research Policy, vol. 41, no. 8, pp. 1325-1343, 2012.

[51] N. van de Wal, C. Boone, V. Gilsing, and B. Walrave, "CEO research orientation, organizational context, and innovation in the pharmaceutical industry," R\&D Management, vol. 50, no. 2, pp. 239-254, 2020.

[52] J. Khuntia, A. Kathuria, M. G. Andrade-Rojas, T. Saldanha, and N. Celly, "How Foreign and Domestic
Firms Differ in Leveraging IT-enabled Supply Chain Information Integration in BOP Markets: The Role of Supplier and Client Business Collaboration," Journal of the Association for Information Systems, vol. 22, no. 3, 2021.

[53] I. Douven, Abduction, Summer 2021 ed. (The Stanford Encyclopedia of Philosophy ). Metaphysics Research Lab, Stanford University, 2021.

[54] A. Dasgupta, P. Karhade, A. Kathuria, and B. Konsynski, "Holding Space for Voices that Do Not Speak: Design Reform of Rating Systems for Platforms in GREAT Economies," in Hawaii International Conference on System Sciences, 2021, p. 2564.

[55] P. Karhade, A. Kathuria, and B. Konsynski, "When Choice Matters: Assortment and Participation for Performance on Digital Platforms," in Hawaii International Conference on System Sciences, 2021, p. 1799.

[56] H. A. Simon, K. W. Deutsch, and M. Shubik, "Designing organizations for an information-rich world," in Computers, communications, and the public interest, ed, 1971, pp. 37--72.

[57] M. Tarafdar, Q. Tu, and T. Ragu-Nathan, "Impact of technostress on end-user satisfaction and performance," Journal of management information systems, vol. 27, no. 3, pp. 303-334, 2010.

[58] S. Vijaykar and P. Karhade, "Remote Virtual Workplaces in the Pandemic: The Case of IT-enabled Service Leadership," in Pacific Asia Conference on Information Systems, 2021.

[59] S. Vijaykar, P. Karhade, and M. Gupta, "Work-FromHome vs. Work-At-Home: A Strategic Conundrum in the Digital Age," in Americas Conference on Information Systems, 2021.

[60] A. Kathuria, J. Khuntia, P. Karhade, and X. Ning, "Don't Ever Take Sides with Anyone against the Family: Family Ownership and Information Management," in Americas Conference on Information Systems, 2019.

[61] L. R. Gomez-Mejia, M. Makri, and M. L. Kintana, "Diversification Decisions in Family-Controlled Firms," Journal of Management Studies, vol. 47, no. 2, pp. 223-252, 2010. 